\title{
Evaluation of a New Recombinant Inbred Line Mapping Population for Genetic Mapping in Groundnut (Arachis hypogaea L.)
}

\author{
M. Sukruth, K. Shirasawa and R.S. Bhat* \\ Department of Biotechnology, UAS, Dharwad, Karnataka (580 005), India \\ *Corresponding author
}

\section{A B S T R A C T}

\begin{tabular}{|c|}
\hline Keywords \\
\hline $\begin{array}{l}\text { Groundnut, Recombinant } \\
\text { inbred lines, Late leaf } \\
\text { spot and rust diseases, } \\
\text { Productivity traits, } \\
\text { Variability, Parental } \\
\text { polymorphism }\end{array}$ \\
\hline Article Info \\
\hline $\begin{array}{l}\text { Accepted: } \\
20 \text { December } 2018 \\
\text { Available Online: } \\
10 \text { January } 2019\end{array}$ \\
\hline
\end{tabular}

\section{Keywords} spot and rust diseases roductivity traits, polymorphism

Article Info

20 December 2018

10 January 2019
A new recombinant inbred line (RIL) population was developed from a late leaf spot (LLS) susceptible mutant (VL 1) and its secondary mutant (110) which was resistant to LLS. The RILs (114) were evaluated for yield, yield components, nutritional and oil quality traits, and response to LLS and rust diseases during the rainy season of 2015 to assess the suitability of the mapping population for mapping these traits. The RILs differed significantly for all the traits studied. Phenotypic coefficient of variation and genotypic coefficient of variation were moderate to high for pod yield, number of pods per plant, pod weight per plant, shelling percentage, test weight, protein, oleic to linoleic acid ratio, kernel yield, oil yield, and LLS and rust score at 70, 80 and 90 days after sowing (DAS). The RILs exhibited normal distribution for all the studied traits except for rust score at 80 and 90 DAS, and shelling percentage. VL 1 and 110 despite being the primary and secondary mutants, showed polymorphism in terms of SNP, CNV and transposable element insertion. Therefore, this RIL population could be of importance for mapping the agronomic and productivity traits.

\section{Introduction}

The cultivated allotetraploid $(2 \mathrm{n}=4 \mathrm{x}=40)$ groundnut (Arachis hypogaea L.) is an important oilseed, food and legume crop with a global production of $42.29 \mathrm{mt}$ from 25.46 mha area. India has the largest groundnutgrowing area of $5.50 \mathrm{mha}$ with $6.30 \mathrm{mt}$ production and $1,150 \mathrm{~kg} / \mathrm{ha}$ productivity (FAO, 2017). Groundnut is regarded as "king of oilseed crops" on account of its diversified uses. Groundnut is an excellent source of plant protein (25-28\%), oil (48-50\%), calcium, iron and vitamin B complex like thiamine, riboflavin, niacin and vitamin $\mathrm{A}$. The haulms are used as livestock feed. Groundnut offers many health benefits like weight gain control (Alper and Mattes, 2002), prevention of cardiovascular diseases, protection against Alzheimer disease and cancer inhibition (Awad et al., 2000).

Groundnut is affected by various diseases and pests which limit its productivity. Conventional breeding had less impact on delivering disease/pest resistant/tolerant cultivars to the farmers because of complex inheritance of the gene controlling the trait, narrow genetic diversity (Pandey et al., 2012) and more over it is highly dependent on 
phenotypic selection. So, with the aid of molecular markers, $\mathrm{n}$ number of genotypes can be screened and best genotype/line can be selected based on genotype of the material rather than phenotype, which further enhances the breeding efficacy in identifying promising progeny/line for the trait of interest.

Genomics-assisted breeding (GAB) has accelerated crop improvement programs for development of improved cultivars. Likewise, LLS (Phaeoisariopsis personata [(Berk. and Curt) Deighton)] and rust (Puccinia arachidis Speg.) is a highly devastating disease among all cultivable areas. Many conventional and molecular breeding strategies were utilised in developing several mapping populations (RILs, NILs, MABCs) to identify significant and major QTL controlling the trait. Many molecular marker systems had been validated using RFLP, AFLP, DAF, SSR, DArT, AhTE and SNPs. In groundnut, GAB has been successful for rust resistance.

QTL and markers were identified (Khedikar et al., 2010; Sujay et al., 2012; Varshney et al., 2014; Kolekar et al., 2016; Zhou et al., 2016, Yeri and Bhat, 2016), validated (Khedikar et al., 2010; Yeri et al., 2014; Sukruth et al., 2015) and used for marker-assisted backcrossing (MABC) (Varshney et al., 2014; Yeri et al., 2016; Pasupuleti et al., 2016; Kolekar et al., 2017). Recently, MABC was also attempted to develop LLS resistant genotypes. However, genomic dissection of LLS resistance is expected to enhance the efficiency of MABC further.

This could be achieved with the use of appropriate mapping populations. In this regard, VL 1, a Valencia type rust resistant mutant was obtained from Dharwad Early Runner (DER), a cross between two fastigiata cultivars, viz. Dh 3-20 and CGC-1 (Gowda et al., 1989). Further EMS mutagenesis in VL 1 gave rise to a Spanish type LLS resistant mutant (110) (Gowda et al., 2010). VL 1 and 110 also differed for main stem length, primary and secondary branches, leaves, pods, kernels, and response to late leaf spot and rust disease.

Considering these phenotypic differences, a RIL population was developed by crossing VL 1 with 110 at UAS, Dharwad, India. The RILs derived from the closely related parents have been shown to be useful in mapping the traits (Hake et al., 2017). Therefore, an effort was made in this study to assess the extent of polymorphism between VL 1 and 110, and to evaluate their RILs for suitability to map the traits in groundnut.

\section{Materials and Methods}

The present study employed a RIL mapping population (MP) derived from VL $1 \times 110$. The field evaluation of 114 RILs along with the parents (VL 1 and 110) was carried out during the rainy season of $2015(\mathrm{R}-15)$ at IABT Garden (E115) of Main Agricultural Research Station, UAS, Dharwad. The experiment was laid out in randomized block design (RBD) with two replications where the plants were spaced at $30 \times 10 \mathrm{~cm}$. All recommended package of practices was followed to raise good crop.

Observations were recorded on the productivity and nutritional traits. Pod yield (PY), number of pods per plant (NPPP), pod weight per plant (PWPP), shelling percentage (SP), test weight (TW) and sound mature kernel weight (SMKW) were recorded as per the groundnut descriptor (IBPGR ICRISAT, 1992). Nutritional traits such as percent protein and oil content of each genotype was estimated by near infrared spectroscopy (NIRS) using FOSS NIR System, 6500 Composite (FOSS Analytical A/S, Denmark) at Seed Quality Testing and Research Laboratory, Seed Unit, UAS, Dharwad. 
Response to LLS and rust were recorded at 70, 80 and 90 days after sowing (DAS) using the modified 9-point scale (1-9 score) (Subbarao et al., 1990) on randomly selected five plants from each genotype. The phenotypic data were analysed for ANOVA, variability and association using Windostat Version 9.1. Frequency distribution of the RILs checked using SPSS Version 16.0. VL 1 and 110 were subjected for whole genome re-sequencing (WGRS) to identify the single nucleotide polymorphism (SNP) and copy number variation (CNV) (Shirasawa et al., 2016).

\section{Results and Discussion}

Groundnut improvement through application of genomic tools requires identification of gene/QTL linked to trait of interest. Development of mapping populations, marker discovery and screening with DNA/molecular markers and identification of QTL associated with economically important target traits are the most important steps in marker assisted selection. Contrasting parents differing for rust and LLS disease could help in dissecting the QTL (Pandey et al., 2017). VL 1 being rust resistant and LLS susceptible and 110 being LLS resistant and rust susceptible allow dissection of rust and LLS resistance. Therefore, the RILs derived from these parents were evaluated for various traits. The RILs differed significantly for all productivity and nutritional traits and response to LLS and rust disease at 70, 80 and 90 DAS (Table 2).

VL 1 recorded a score of 8 for LLS at 90 DAS, whereas 110 recorded a score of 3.5. However, not much difference was observed between the parents for the score of rust. The parents also differed significantly for pod yield, number of pods per plant, pod weight per plant, shelling percentage, test weight, sound mature kernel weight, protein, oil, oleic to linoleic acid ratio, kernel and oil yield (presented in table 2 along with $\mathrm{CV}$ and $\mathrm{CD}$ ).
Considerably wide range was observed among the RILs for all productivity, nutritional and, LLS and rust disease reaction traits.

High PCV and GCV were observed for number of pods per plant, pod weight per plant, oleic to linoleic acid ratio. Traits such as test weight, protein and LLS disease reaction at 90 DAS exhibited moderate PCV and GCV, whereas low PCV and GCV was observed for sound mature kernel weight and oil content (Table 4). Pod yield, kernel yield, oil yield, LLS disease response at 70 and 80 DAS, and rust disease response at 70,80 and 90 DAS recorded high PCV and moderate GCV. Shelling percentage exhibited moderate PCV with low GCV.

The distribution of the RILs of VL $1 \times 110$ for quantitative characters (productivity, nutrition and disease reaction) was studied by working out the Skewness and kurtosis (Zhang et al., 2014) using SPSS version 16.0 software. Skewness ranging from -2 to +2 suggested a normal distribution, where 0 skewness indicated a perfect symmetric distribution. Skewness below or above the range $(-2$ to +2$)$ indicated a negatively and positively skewed distribution, respectively (Lomax and HahsVaughn, 2013). Kurtosis ranging from -3 to +3 indicated a normal distribution. RILs showed normal distribution for all the traits studied except for shelling percentage. Rust disease score at 80 and 90 DAS showed skewed kurtosis (Table 1 and Fig. 1).

Knowledge on the trait association would help in trait mapping. Pod yield had positive and significant association with pod weight per plant, shelling percentage, test weight, sound mature kernel weight, kernel and oil yield. Number of pods per plant was positively and significantly associated with test weight, LLS score at $90 \mathrm{DAS}$, and rust score at 80 and 90 DAS. Pod weight per plant, shelling percentage, test weight and sound mature 
kernel weight had positive and significant association with kernel and oil yield. Similarly, kernel and oil yield, LLS and rust disease response at 70,80 and $90 \mathrm{DAS}$ are positively and significantly associated with each other. But, LLS and rust disease reaction was observed to be negatively associated with each other (Table 3).

Fig.1 Frequency distribution of the RILs of VL $1 \times 110$ population for LLS and rust reaction
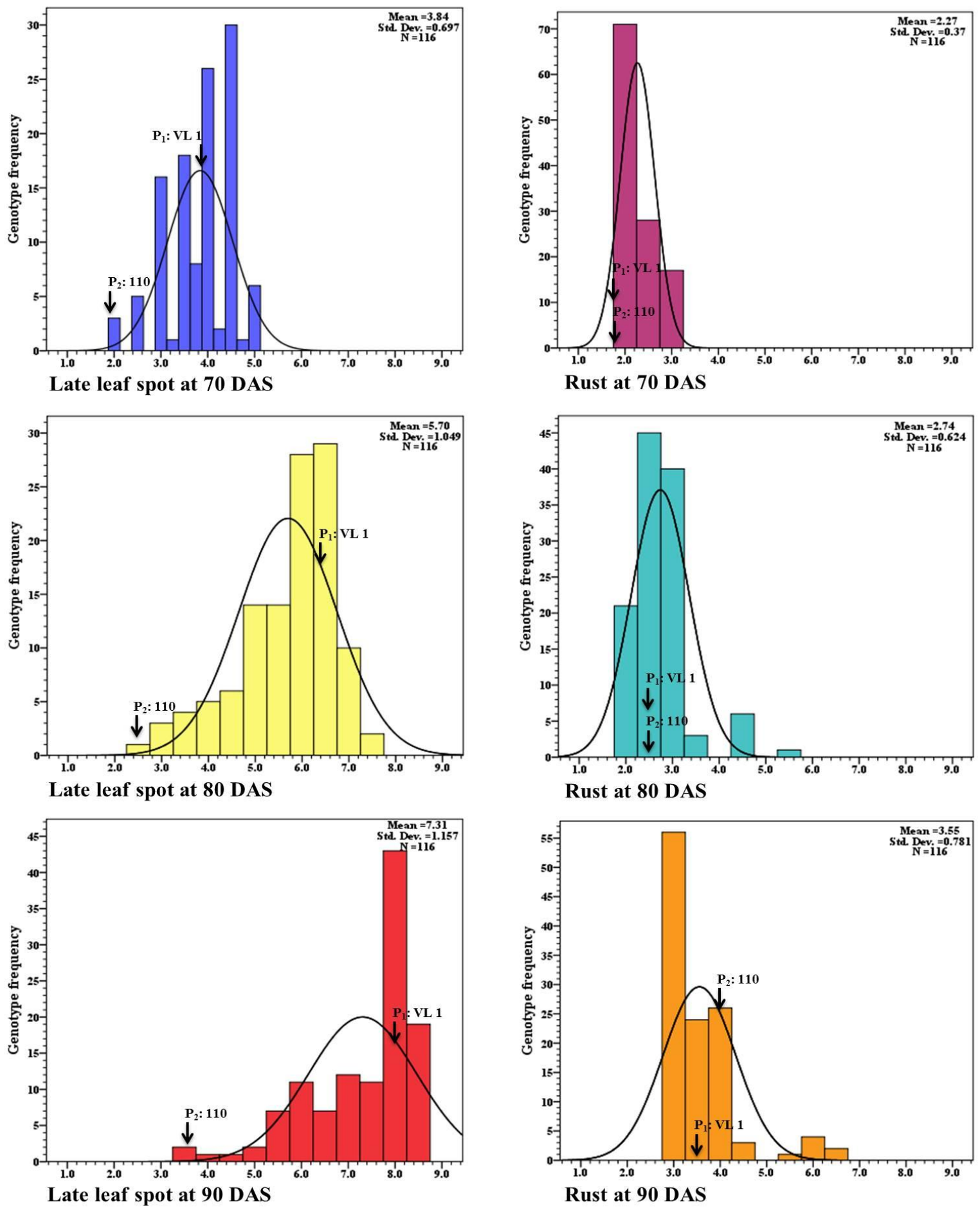
Fig.2 Copy number variation in 110 when compared to VL 1

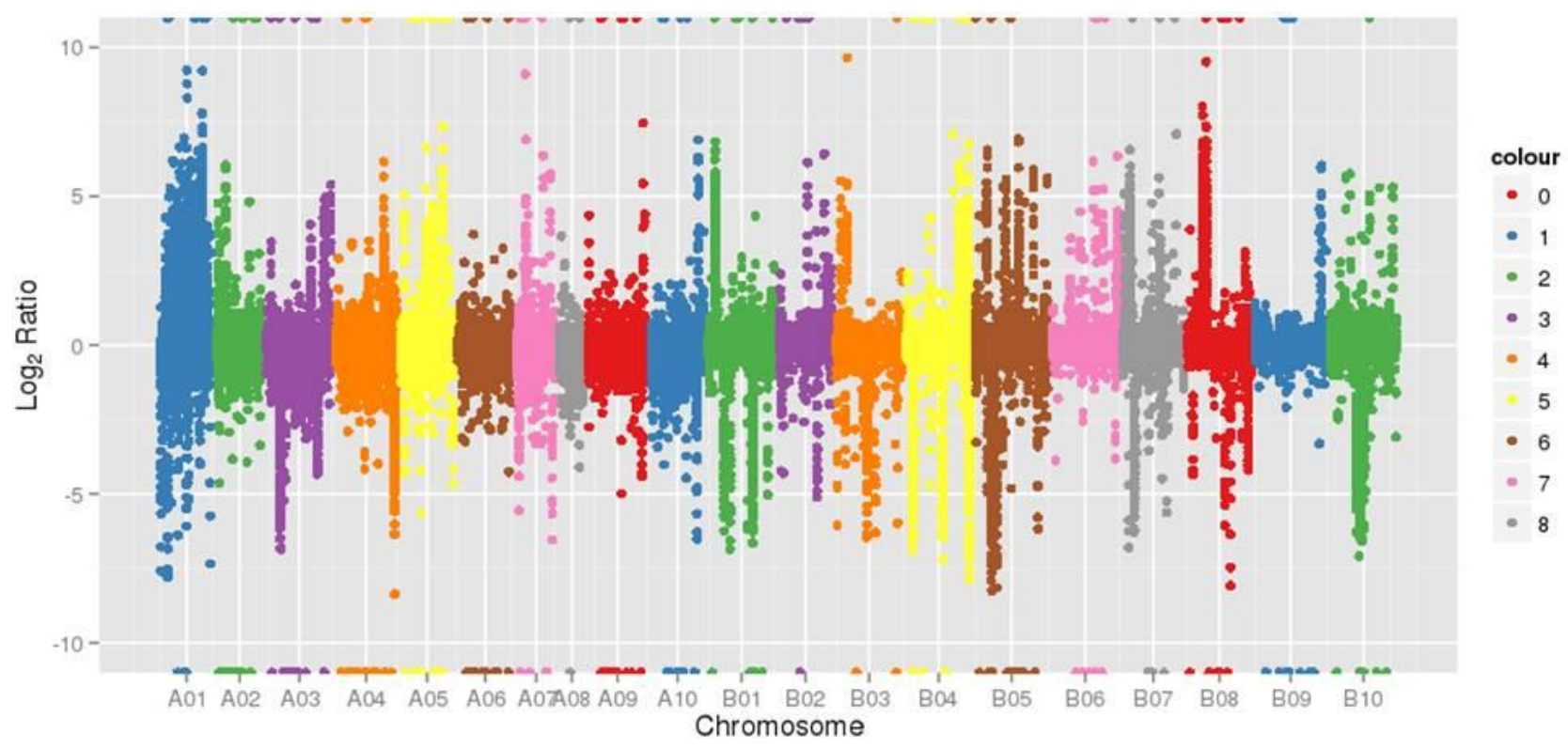

Table.1 Frequency distribution of the RILS of VL $1 \times 110$ for productivity, nutritional and disease reaction traits

\begin{tabular}{|l|l|l|l|}
\hline Traits & Skewness & Kurtosis & Distribution \\
\hline PY & -0.27 & -0.192 & Normal \\
\hline NPPP & 0.402 & -0.45 & Normal \\
\hline PWPP & 1.269 & 2.335 & Normal \\
\hline SP & -3.923 & 23.169 & Skewed kurtosis \\
\hline TW & -0.032 & -0.397 & Normal \\
\hline SMKW & -1.141 & 1.484 & Normal \\
\hline PROTEIN & -0.846 & 1.231 & Normal \\
\hline OIL & -0.316 & 0.959 & Normal \\
\hline O/L & 1.495 & 2.231 & Normal \\
\hline KY & -0.564 & 0.956 & Normal \\
\hline OY & -0.433 & 0.742 & Normal \\
\hline LLS_70 & -0.561 & -0.139 & Normal \\
\hline LLS_80 & -0.954 & 0.53 & Normal \\
\hline LLS_90 & -1.235 & 1.094 & Normal \\
\hline RUST_70 & 0.996 & -0.458 & Normal \\
\hline RUST_80 & 2.015 & 4.415 & Skewed kurtosis \\
\hline RUST_90 & 2.094 & 4.738 & Skewed kurtosis \\
\hline
\end{tabular}

PY: Pod yield (kg/ha); NPPP: Number of pods per plant; PWPP: Pod weight per plant (g); SP: Shelling percentage (\%); TW: Test weight (g); SMKW: Sound mature kernel weight (\%);O/L: Oleic to linoleic acid ratio; KY: Kernel yield (kg/ha); OY: Oil yield (kg/ha); LLS_70: Late leaf spot score at 70 days after sowing (DAS); LLS_80: Late leaf spot score at 80 DAS; LLS_90: Late leaf spot score at 90 DAS; RUST_70: Rust score at 70 DAS; RUST_80: Rust score at 80 DAS; RUST_90: Rust score at 90 DAS 
Table.2 ANOVA for productivity, nutritional and disease reaction traits in the RIL population of VL $1 \times 110$

\begin{tabular}{|c|c|c|c|c|c|c|c|c|c|c|c|c|c|c|c|c|c|c|}
\hline $\begin{array}{l}\text { Source of } \\
\text { variation }\end{array}$ & df & PY & NPPP & PWPP & SP & TW & SMKW & PROTEIN & OIL & $\mathrm{O} / \mathrm{L}$ & KY & OY & LLS_70 & LLS_80 & LLS_90 & RUST_70 & RUST_80 & RUST_90 \\
\hline $\begin{array}{l}\text { Replication } \\
\text { MSS }\end{array}$ & 1 & $68.2 \mathrm{E} 03$ & 1.46 & 0.21 & 11.65 & 44.31 & 0.34 & 0.03 & 1.70 & 0.22 & $33.4 \mathrm{E} 02$ & $33.3 \mathrm{E} 02$ & 1.24 & 2.08 & 5.28 & 0.15 & 0.52 & 0.06 \\
\hline $\begin{array}{l}\text { Genotype } \\
\text { MSS }\end{array}$ & 115 & $80.1 \mathrm{E} 04 * *$ & $31.55 * *$ & $105.95^{* *}$ & $85.85^{* * *}$ & $158.63 * *$ & $10.06^{* *}$ & 20.18 ** & $11.58^{* * *}$ & $0.59 * *$ & $53.5 \mathrm{E} 04 * *$ & $13.4 \mathrm{E} 04 * *$ & $0.97 * *$ & $2.19 * *$ & $2.67 * *$ & $0.27 * *$ & $0.77 * *$ & $1.22 * *$ \\
\hline Error MSS & 115 & $34.6 \mathrm{E} 04$ & 1.87 & 1.00 & 41.02 & 28.79 & 6.00 & 0.98 & 0.79 & 0.11 & 22.3E04 & $52.0 \mathrm{E} 03$ & 0.51 & 1.09 & 1.54 & 0.17 & 0.25 & 0.23 \\
\hline CV & & 14.95 & 7.85 & 10.47 & 9.50 & 8.15 & 2.47 & 3.30 & 1.71 & 18.93 & 18.42 & 18.75 & 19.23 & 17.59 & 16.91 & 11.47 & 11.47 & 8.43 \\
\hline CD at $5 \%$ & & 641.09 & 1.97 & 2.43 & 7.93 & 5.90 & 3.19 & 1.20 & 1.01 & 0.42 & 507.95 & 245.69 & 0.87 & 1.23 & 1.55 & 0.42 & 0.50 & 0.48 \\
\hline SEm \pm & & 433.05 & 1.37 & 1.65 & 5.64 & 4.05 & 2.29 & 0.97 & 0.82 & 0.33 & 339.45 & 164.48 & 0.62 & 0.87 & 1.11 & 0.25 & 0.30 & 0.28 \\
\hline
\end{tabular}

*, **: Significant at 5\% and 1\%, respectively; df: degrees of freedom; CV: Coefficient of variation; CD: Critical difference; SEm \pm : Standard error of mean; MSS: Mean sum of square: PY: Pod yield (kg/ha); NPPP: Number of pods per plant; PWPP: Pod weight per plant (g); SP: Shelling percentage (\%); TW: Test weight (g); SMKW: Sound mature kernel weight (\%);O/L: Oleic to linoleic acid ratio; KY: Kernel yield (kg/ha); OY: Oil yield (kg/ha); LLS_70: Late leaf spot score at 70 days after sowing (DAS); LLS_80: Late leaf spot score at 80 DAS; LLS_90: Late leaf spot score at 90 DAS; RUST_70: Rust score at 70 DAS; RUST_80: Rust score at 80 DAS; RUST_90: Rust score at 90 DAS

Table.3 Phenotypic correlation coefficients for productivity, nutritional and disease reaction traits in the RILs of VL1 $\times 110$ population

\begin{tabular}{|c|c|c|c|c|c|c|c|c|c|c|c|c|c|c|c|c|c|}
\hline Traits & PY & NPPP & PWPP & SP & TW & SMKW & PROTEIN & OIL & $\mathrm{O} / \mathrm{L}$ & KY & OY & LLS_70 & LLS_80 & LLS_90 & RUST_70 & RUST_80 & RUST_90 \\
\hline PY & 1 & & & & & & & & & & & & & & & & \\
\hline NPPP & 0.146 & 1 & & & & & & & & & & & & & & & \\
\hline PWPP & $0.204^{*}$ & 0.082 & 1 & & & & & & & & & & & & & & \\
\hline SP & $0.728 * *$ & 0.077 & 0.159 & 1 & & & & & & & & & & & & & \\
\hline TW & $0.250 * *$ & $0.194 *$ & 0.132 & $0.250^{* *}$ & 1 & & & & & & & & & & & & \\
\hline SMKW & $0.236^{*}$ & -0.069 & -0.007 & $0.338^{* * *}$ & -0.034 & 1 & & & & & & & & & & & \\
\hline PROTEIN & -0.018 & -0.036 & -0.038 & -0.105 & 0.019 & -0.027 & 1 & & & & & & & & & & \\
\hline OIL & 0.069 & -0.022 & 0.086 & -0.038 & -0.031 & 0.007 & -0.078 & 1 & & & & & & & & & \\
\hline OLR & 0.084 & 0.002 & 0.107 & 0.112 & 0.048 & 0.118 & $-0.207 *$ & -0.017 & 1 & & & & & & & & \\
\hline KY & $0.967 * *$ & 0.113 & $0.201 *$ & $0.848 * *$ & $0.282 * *$ & $0.281 * *$ & -0.055 & 0.054 & 0.091 & 1 & & & & & & & \\
\hline OY & $0.954 * *$ & 0.113 & $0.211 *$ & $0.819 * *$ & $0.261 * *$ & $0.272 * *$ & -0.068 & $0.229 *$ & 0.081 & $0.983 * *$ & 1 & & & & & & \\
\hline LLS_70 & 0.005 & 0.134 & -0.032 & -0.034 & -0.002 & 0.001 & -0.067 & 0.111 & 0.137 & 0.005 & 0.028 & 1 & & & & & \\
\hline LLS_80 & -0.044 & 0.096 & -0.101 & -0.013 & 0.003 & -0.048 & -0.043 & 0.002 & -0.017 & -0.025 & $\overline{-} .029$ & $0.568 * *$ & 1 & & & & \\
\hline LLS_90 & 0.138 & $0.183^{*}$ & -0.092 & $0.182 *$ & 0.089 & 0.098 & -0.133 & 0.028 & 0.065 & 0.178 & 0.176 & $0.451 * *$ & $0.766^{* *}$ & 1 & & & \\
\hline RUST_70 & 0.032 & 0.172 & 0.038 & -0.004 & -0.024 & -0.041 & -0.052 & 0.118 & $0.203^{*}$ & 0.015 & 0.041 & 0.069 & 0.113 & 0.131 & 1 & & \\
\hline RUST_80 & 0.095 & $0.214^{*}$ & 0.126 & 0.001 & $0.270^{* *}$ & 0.004 & -0.015 & -0.064 & 0.176 & 0.063 & 0.044 & -0.068 & -0.066 & 0.082 & $0.458^{* *}$ & 1 & \\
\hline RUST_90 & 0.134 & $0.216^{*}$ & 0.016 & 0.066 & 0.163 & 0.081 & -0.022 & -0.015 & 0.082 & 0.108 & 0.111 & -0.096 & -0.166 & -0.051 & $0.268^{* *}$ & $0.630^{* * *}$ & 1 \\
\hline
\end{tabular}

PY: Pod yield (kg/ha); NPPP: Number of pods per plant; PWPP: Pod weight per plant (g); SP: Shelling percentage (\%); TW: Test weight (g); SMKW: Sound mature kernel weight (\%); O/L: Oleic to linoleic acid ratio; KY: Kernel yield (kg/ha); OY: Oil yield (kg/ha); LLS_70: Late leaf spot score at 70 days after sowing (DAS); LLS_80: Late leaf spot score at 80 DAS; LLS_90: Late leaf spot score at 90 DAS; RUST_70: Rust score at 70 DAS; RUST_80: Rust score at 80 DAS; RUST_90: Rust score at 90 DAS 
Table.4 Mean, range and genetic variability components for productivity, nutritional and disease resistance traits among the RILs of VL1 $\times 110$

\begin{tabular}{|l|l|l|l|l|l|l|l|}
\hline Traits & Mean & Minimum & Maximum & GCV $(\boldsymbol{\%})$ & PCV $(\boldsymbol{\%})$ & $\mathbf{h}^{\mathbf{b}} \mathbf{b s}$ & GAM \\
\hline PY & 2944.44 & 1322.22 & 4566.67 & 14.51 & 23.05 & 39.63 & 18.82 \\
\hline NPPP & 18.50 & 9.83 & 27.17 & 22.03 & 23.37 & 88.81 & 42.76 \\
\hline PWPP & 24.50 & 4.37 & 44.62 & 46.59 & 47.03 & 98.13 & 95.08 \\
\hline SP & 50.83 & 23.50 & 78.15 & 6.74 & 11.34 & 35.34 & 8.25 \\
\hline TW & 52.38 & 30.95 & 73.80 & 15.47 & 18.59 & 69.28 & 26.53 \\
\hline SMKW & 91.75 & 86.00 & 97.50 & 1.51 & 3.01 & 25.28 & 7.57 \\
\hline PROTEIN & 27.76 & 19.11 & 36.42 & 10.48 & 11.00 & 90.74 & 20.56 \\
\hline OIL & 46.22 & 38.98 & 53.46 & 4.87 & 5.21 & 87.23 & 9.37 \\
\hline O/L & 2.21 & 0.82 & 3.60 & 28.06 & 33.88 & 68.57 & 47.86 \\
\hline KY & 1875.03 & 357.39 & 3392.67 & 16.92 & 26.38 & 41.12 & 22.35 \\
\hline OY & 902.80 & 165.45 & 1640.15 & 18.19 & 27.36 & 44.17 & 24.90 \\
\hline LLS_70 & 3.50 & 2.00 & 5.00 & 12.50 & 22.42 & 31.08 & 14.36 \\
\hline LLS_80 & 5.00 & 2.50 & 7.50 & 13.01 & 22.47 & 33.54 & 15.53 \\
\hline LLS_90 & 6.00 & 3.50 & 8.50 & 10.29 & 19.86 & 26.84 & 10.98 \\
\hline RUST_70 & 2.50 & 2.00 & 3.00 & 9.86 & 20.69 & 22.73 & 9.69 \\
\hline RUST_80 & 3.75 & 2.00 & 5.50 & 18.63 & 26.09 & 50.98 & 27.40 \\
\hline RUST_90 & 4.75 & 3.00 & 6.50 & 19.81 & 23.97 & 68.28 & 33.72 \\
\hline
\end{tabular}

Vg: Genotypic variance; Vp: Phenotypic variance; GCV: Genotypic coefficient of variation (\%); PCV: Phenotypic coefficient of variation (\%); $h^{2}$ bs: Heritability in broad sense (\%); GAM: Genetic advance as percent of mean; PY: Pod yield (kg/ha); NPPP: Number of pods per plant; PWPP: Pod weight per plant (g); SP: Shelling percentage (\%); TW: Test weight (g); SMKW: Sound mature kernel weight (\%); O/L: Oleic to linoleic acid ratio; KY: Kernel yield (kg/ha); OY: Oil yield (kg/ha); LLS_70: Late leaf spot score at 70 days after sowing (DAS); LLS_80: Late leaf spot score at 80 DAS; LLS_90: Late leaf spot score at 90 DAS; RUST_70: Rust score at 70 DAS; RUST_80: Rust score at 80 DAS; RUST_90: Rust score at 90 DAS

Table.5 Total number of SNPs between VL 1 and 110

\begin{tabular}{|l|l|r|l|r|}
\hline Sl. No. & A chromosome & No. of SNPs & B chromosome & No. of SNPs \\
\hline $\mathbf{1}$ & Aradu.A01 & $2,54,108$ & Araip.B01 & 13,661 \\
\hline $\mathbf{2}$ & Aradu.A02 & 8,083 & Araip.B02 & 11,064 \\
\hline $\mathbf{3}$ & Aradu.A03 & 6,659 & Araip.B03 & 9,065 \\
\hline $\mathbf{4}$ & Aradu.A04 & 4,032 & Araip.B04 & 9,263 \\
\hline $\mathbf{5}$ & Aradu.A05 & 7,315 & Araip.B05 & 15,964 \\
\hline $\mathbf{6}$ & Aradu.A06 & 6,554 & Araip.B06 & 14,351 \\
\hline $\mathbf{7}$ & Aradu.A07 & 4,289 & Araip.B07 & 14,065 \\
\hline $\mathbf{8}$ & Aradu.A08 & 2,180 & Araip.B08 & 8,837 \\
\hline $\mathbf{9}$ & Aradu.A09 & 8,289 & Araip.B09 & 1,514 \\
\hline $\mathbf{1 0}$ & Aradu.A10 & 6,536 & Araip.B10 & 15,046 \\
\hline Total & & $3,08,045$ & & $1,12,830$ \\
\hline
\end{tabular}

Aradu: Arachis duranensis; Araip: Arachis ipaensis 
Apart from the presence of significant variability among the RILs, genetic relatedness/similarity between the parents would also contribute for efficient detection of QTL by avoiding background noise (Chen et al., 2008). With this objective, VL 1 and 110 were compared using the WGRS data for SNP and CNV.

The WGRS reads of VL 1 and 110 were compared with those of the two groundnut progenitors i.e., A. duranensis (A genome) and A. ipaensis (B genome). A total of 4,20,875 SNPs $(3,08,045$ from A sub-genome and 1,12,830 from B sub-genome) were detected (Table 5; Fig. 3). The number of SNPs ranged from 2,180 (A08 chromosome) to $2,54,108$ (A01 chromosome). In B subgenome SNPs ranged from 1,514 (B09 chromosome) to 15,964 (B05 chromosome).

CNVs are genomic rearrangements resulting from gains or losses of DNA segments. This type of polymorphism has recently been shown to be a key contributor to intra-species genetic variation, along with single-nucleotide polymorphisms and short insertion-deletion polymorphisms. In many of the cases, CNVs of specific genes have been linked to important traits such as flowering time, plant height and resistance to biotic and abiotic stress. Hence, an effort was made to check the copy number variations (CNVs) between VL 1 and 110 mutant genotypes. A total of 600 genomic regions showed significant $\mathrm{CNVs}$ across 18 chromosomes (Fig 2). A and B chromosome consists of 163 and 437 significant CNVs.

VL 1 and 110 also showed polymorphism of 2.7 to $66.1 \%$ with AhTE markers (Hake et al., 2017). The genetic differences between VL 1 and 110 in terms of SNPs and CNVs could be useful in mapping the traits which showed considerable variability among the RILs. The QTL and the markers identified from the marker-trait association studies will be useful for molecular breeding in groundnut.

\section{Acknowledgement}

Funds received from BRNS project (no. 2013/35/12/BRNS), and the DST-JSPS Bilateral Program is gratefully acknowledged.

\section{References}

Alper, C. and Mattes, R. 2002. Effects of chronic peanut consumption on energy balance and hedonics. Int. J. Obes. Relat. Metab. Disord. 26 (8): 11291137.

Awad, A., Downie, A., Fink, C., and Kim, U. 2000. Dietary phytosterol inhibits the growth and metastasis of MDA-MB231 human breast cancer cells grown in SCID mice. Anticancer Res. 20 (2A): 821-824.

Chen, Y., Chao, Q., Tan, G., Zhao, J., Zhang, M., and Ji, Q. 2008. Identification and fine-mapping of a major QTL conferring resistance against head smut in maize. Theor Appl Genet. 117 (8): 1241.

FAO. 2017. Food and agriculture organization of the United Nations. FAOSTAT database.

http://www.fao.org/faostat/collections,s ubset=Agriculture .

Gowda, M. V. C., Bhat, R. S., Motagi, B. N., Sujay, V., Varshakumari and Bhat, R. S. 2010. Association of high-frequency origin of late leaf spot resistant mutants with AhMITE1 transposition in peanut. Plant Breed. 129 (5): 567-569.

Gowda, M., Nadaf, H. L., and Giriraj, K. 1989. A new growth habit variant of taxonomical importance in groundnut (Arachis hypogaea L.). Intl. Arachis Newslet. 6 (6): 48-54. 
Hake A. A., Shirasawa, K., Yadawad, A., Sukruth, M., Patil, M., Nayak, S. N., Lingaraju, S., Patil, P.V., Nadaf, H. L., Gowda, M.V.C., and Bhat, R. S. 2017. Mapping of important taxonomic and productivity traits using genic and nongenic transposable element markers in peanut (Arachis hypogaea L.). PLoS One. 12: e0186113.

IBPGRIICRISAT. 1992. Descriptors for groundnut. IBPGR, Roam, Italy and ICRISAT, Patancheru, Andhra Pradesh, India, pp. 125.

Khedikar, Y., Gowda, M. V. C., Sarvamangala, C., Patgar, K., Upadhyaya, H., and Varshney, R. 2010. A QTL study on late leaf spot and rust revealed one major QTL for molecular breeding for rust resistance in groundnut (Arachis hypogaea L.). Theor Appl Genet. 121: 971-984.

Kolekar, R. M., Sujay, V., Shirasawa, K., Sukruth, M., Khedikar, Y. P., Gowda, M. V. C., and Bhat, R. S. 2016. QTL mapping for late leaf spot and rust resistance using an improved genetic map and extensive phenotypic data on a recombinant inbred line population in peanut (Arachis hypogaea L.). Euphytica. 209: 147-156.

Kolekar, R. M., Sukruth, M., Shirasawa, K., Nadaf, H. L., Motagi, B. N., Lingaraju, S., Patil, P. V., and Bhat, R. S. 2017. Marker-assisted backcrossing to develop foliar disease resistant genotypes in TMV 2 variety of peanut (Arachis hypogaea L.). Plant Breed. 136: 948-953.

Lomax, R. G., and Hahs-Vaughn, D. L. 2013. An Introduction to Statistical Concepts3rd edition. Routledge, Taylor and Francis group, New York, United States of America.

Pandey, M. K., Gautami, B., Jayakumar, T., Sriswathi, M., Upadhyaya, H. D., Gowda, M. V. C., Radhakrishnan, T.,
Bertioli, D. J., Knapp, S. J., Cook, D. R., and Varshney, R. K. 2012. Highly informative genic and genomic SSR markers to facilitate molecular breeding in cultivated groundnut (Arachis hypogaea L.). Plant Breed. 131: 139147.

Pandey, M. K., Khan Amir, W., Singh, V. K., Vishwakarma, M. K., Yaduru, S., Kumar, V., and Varshney, R. K. 2016. QTL-seq approach identified genomic regions and diagnostic markers for rust and late leaf spot resistance in groundnut (Arachis hypogaea L.). Plant Biotechnology J. 15, 927-941.

Pandey, M. K., Wang, H., Khera, P., Vishwakarma, M. K., Kale, S. M., Culbreath, A. K., Holbrook, C. C., Wang, X., Varshney, R. K., and Guo, B. 2017. Genetic dissection of novel QTLs for resistance to leaf spots and tomato spotted wilt virus in peanut (Arachis hypogaea L.). Front Plant Sci 8: 25

Pasupuleti, J., Pandey, M. K., Manohar, S. S., Variath, M. T., Nallathambi, P., Nadaf, H. L., and Varshney, R. K. 2016. Foliar fungal disease resistant introgression lines of groundnut (Arachis hypogaea L.) record higher pod and haulm yield in multilocation testing. Plant Breed. 135: 355-366.

Shirasawa, K., Hirakawa, H., Nunome, T., Tabata, S., and Isobe, S. 2016. Genomewide survey of artificial mutations induced by ethyl methanesulfonate and gamma rays in tomato. Plant Biotechnol J. 14 (1): 51-60.

Subbarao, P.V., Subramanyam, P., and Reddy. P. M. 1990. A modified nine points diseases scale for assessment of rust and late leaf spot of groundnut. Paper presented In: Second International Congress of French Phytopathological Society, Montpellier, France. pp. 25. 
Sujay, V., Gowda, M. V. C., Pandey, M. K., Bhat, R. S., Khedikar, Y. P., Nadaf, H. L., and Varshney, R. K. 2012. QTL analysis and construction of consensus genetic map for foliar disease resistance based on two RIL populations in cultivated groundnut (Arachis hypogaea L.). Mol Breed. 30, 773-788.

Sukruth, M., Paratwagh, S. A., Sujay, V., Kumari, V., Gowda, M. V. C., Nadaf, H. L., and Bhat, R. S. 2015. Validation of markers linked to late leaf spot and rust resistance, and selection of superior genotypes among diverse recombinant inbred lines and backcross lines in peanut (Arachis hypogaea L.). Euphytica. 204: 343-351.

Varshney, R. K., Pandey, M. K., Pasupuleti, J., Nigam, S. N., Sudini, H., Gowda, M. V. C., Sriswathi, M., Radhakrishan, T., Manohar, S. S., and Patne, N. 2014. Marker-assisted introgression of a QTL region to improve rust resistance in three elite and popular varieties of peanut (Arachis hypogaea L.). Theor Appl Genet. 127 (8): 1771-1781.
Yeri, S. B. and Bhat, R. S. 2016. Development of late leaf spot and rust resistant backcross lines in JL 24 variety of groundnut (Arachis hypogaea L.). Electronic Journal of Plant Breed. 7, 37-41.

Yeri, S. B., Shirasawa, K., Pandey, M. K., Gowda, M. V. C., Sujay, V., Shriswathi, M., and Bhat, R. S. 2014. Development of NILs from heterogeneous inbred families for validating the rust resistance QTLs in peanut (Arachis hypogaea L.). Plant Breed. 133: 80-85.

Zhang, H., Hui, G., Luo, Q., Sun, Y., and Liu, X. 2014. Descriptive statistics and correlation analysis of agronomic traits in a maize recombinant inbred line population. Genet. Mol. Res. 13 (1): 457-461.

Zhou, X., Xia, Y., Liao, J., Liu, K., Li, Q., Dong, Y., Ren, X., Chen, Y., Huang, L., and Liao, B. 2016. Quantitative trait locus analysis of late leaf spot resistance and plant-type-related traits in cultivated peanut (Arachis hypogaea L.) under multi-environments. PLoS ONE. 11: e0166873.

\section{How to cite this article:}

Sukruth, M., K. Shirasawa and Bhat, R.S. 2019. Evaluation of a New Recombinant Inbred Line Mapping Population for Genetic Mapping in Groundnut (Arachis hypogaea L.). Int.J.Curr.Microbiol.App.Sci. 7(08): 2956-2965. doi: https://doi.org/10.20546/ijcmas.2019.801.314 